\title{
Temperature and Heat Partition Testing in the Cutting Zone for Turning AISI 321 Steel
}

\author{
Marian Bartoszuk* \\ Opole University of Technology, Faculty of Mechanical Engineering, Poland
}

This article shows selected results of experimental tests and the results of analytical and numerical modelling of the thermal characteristics of the cutting process. The tests were conducted for the case of the dry turning of austenitic steel AISI 321 with cutting tools with a flat rake face. The research aimed to determine the actual division of thermal fluxes in the zone of contact between the chip and the rake face. As a result of such work, a formula for a new heat partition coefficient and a formula for calculating the average contact temperature were developed. The results showed that the formulas developed can be a useful tool to estimate heat distribution in the cutting zone quickly.

Keywords: cutting process, numerical modelling, contact temperature, heat partition

Highlights

- $\quad$ This article examines the heat dissipation in the chip-to-rake face interface.

- $\quad$ The analyses were carried out using the results of experimental research, analytical modelling, and computer simulations.

- A formula was developed for a new heat partition coefficient at the chip-to-cutting tool interface.

- A new formula for determining the average contact temperature was proposed.

\section{INTRODUCTION}

Heat is emitted while machining metal materials. This heat is generated by the plastic deformation of the workpiece material and by the friction of the cutting tool surface against the workpiece. It is believed that it is the high temperature and distribution of heat in the cutting zone that are the main factors determining tool wear. The negative influence of temperature on tool life is particularly important in dry cutting at high cutting speeds [1] and [2]. Economic and environmental pressures require the cutting to be carried under precisely these conditions. The amount of heat generated during the cutting process depends mainly on the machining parameters and the machinability of the workpiece material. In contrast, the distribution of heat between the tool, chip and workpiece depends mainly on the mutual ratio of the thermophysical properties of the cutting tool material and the workpiece material [3] and [1]. The most important are thermal conductivity, thermal diffusivity, and heat transfer coefficient. In industrial practice, tool manufacturers use advanced protective coatings to reduce the negative impact of cutting temperatures. The chemical compositions of coatings and their structure are constantly changing. The ever-increasing demands of tool users dictate these changes.

For exploratory purposes, the temperature values in the individual areas of the cutting zone can be determined using appropriate mathematical models, the methodology proposed by Shaw [3], Reznikov
[4] or Silin [5] can be mentioned. These calculations are often based on heat partition coefficients, which determine how much of the heat flux enters the tool. Nowadays, the analyses of heat distribution in the cutting zone are often supported by the results of computer simulations or thermographic measurements. The finite element method (FEM) [6] and [7], as well as the boundary element method (BEM) [8] and [9], are usually used for computer simulations, less often the finite difference method (FDM) [1] and [10] is utilised. The wide popularity of these calculation methods is due to their universality. They allow for the simultaneous observation of the stress distribution of temperature fields deformation, etc. The smoothed-particle hydrodynamics (SPH) method has similar computational capabilities [11] and [12]. However, it is not very common in machining.

The least frequently used is the method of elementary balances (MEB) being a variation of the FDM method. In this method, usually only the heat distribution in the cutting zone is tested [13]. For example, using this method, Bartoszuk and Grzesik [10] researched the temperature distribution and direction of flow of heat fluxes along the length of the chip-tool interface. Any calculation using this method may be carried out considering the area of the moving chip or without the chip (only for the cutting tool itself) [1]. In the latter case, however, it is necessary to know the heat partition coefficient. This coefficient allows you to calculate how much heat is introduced into the cutting tool area through the length of the chiptool interface. However, the calculation formulas of 
commonly used heat partition coefficients (according to Shaw [3], Reznikov [4] or Kato-Fujii heat partition coefficient [5]) were defined many years ago. At that time, high-speed steel tools and first-generation carbide cutting tools were commonly used. Therefore, the machining parameters were modest. Nowadays, mainly state-of-the-art carbide tool materials and much higher values of cutting parameters are used. Therefore, calculations made with the help of these coefficients may be subject to material error.

In recent years, several papers have appeared in the literature describing heat distribution in the contact zone. However, there is little research in this area, and it is usually related to the topic of estimating the factors influencing the change in heat conduction at the chip-cutting tool interface. For example, Jam and Fard [14] used the reverse procedure to estimate the thermal conductivity at the chip-tool interface. The study was conducted for carbide cutting tools and AISI 1045 steel. The paper shows that it is possible to increase the accuracy of numerical calculations by correcting the heat partition coefficient.

Jin et al. [15] examined how the heat distribution in the cutting zone occurs and what effect the basic protective coatings have on heat dissipation. The research was conducted for H13 steel. In contrast, Jinfu and Liu [16] studied the changes in the heat partition coefficient over time and showed that the value of the heat partition coefficient decreases with increasing cutting speed. Carbide cutting tools and Inconel 718 were tested. Similar issues were addressed by Zemzemi et al. [17]. They studied the cutting of Inconel 718 with carbide and CBN cutting inserts. Similarly to previous researchers, they demonstrated that the value of the heat partition coefficient decreases as the cutting speed increases. It should be noted that a major shortcoming of these works is the assumption of constant and temperature-independent thermo-physical properties of the tested materials.

To summarize, the calculation formulas used thus far for heat partition coefficients do not work very well for modern tool materials, especially at higher cutting speeds. An extensive analysis of the literature has shown that there is no alternative calculation methodology that reliably describes the heat distribution in the chip-tool interface for modern carbide tools and the machining parameters recommended by manufacturers. Recognizing the shortage of knowledge in this area, the author attempted to develop a new heat partition coefficient that better describes the heat distribution between the chip and cutting tool, specifically one that will perform well in modern tool materials at higher cutting speeds.
In order to determine the new coefficient of heat partition at the interface between the cutting tool and the workpiece material, comprehensive analyses of the cutting process were carried out. The activities included experimental tests of the turning process, analytical temperature modelling, and numerical modelling of heat dissipation in the cutting zone. It was only on the basis of such research that a formula for a new heat partition coefficient and a formula for calculating the average temperature of the chip-tool interface were developed. The results obtained were compared with the results of the experiment. In order to better understand the basic laws governing the division of heat at the interface between the cutting insert and the workpiece material, the consideration was limited to the case of dry turning with a carbide tool with a flat rake face.

\section{TEST METHODOLOGY}

The case of orthogonal cutting of AISI 321 steel with an uncoated $\mathrm{H} 10 \mathrm{~F}$ carbide cutting insert was selected for testing. The tests were carried out using the PTNGR 2020-16 tool holder and the TNMA 160408 cutting insert with a flat rake face (Table 1). No cooling lubricant was used during the machining.

Table 1. Specification of the angles of the tool cutting insert

\begin{tabular}{lcc}
\hline Angle & Designation & Value [ $\left.{ }^{0}\right]$ \\
\hline Rake & $\gamma_{n}$ & -5 \\
\hline Clearance & $\alpha_{n}$ & 5 \\
\hline entering - main & $\kappa_{r}$ & 90 \\
\hline entering - auxiliary & $\kappa_{r}{ }^{\prime}$ & - \\
\hline cutting edge inclination & $\lambda_{s}$ & -6 \\
\hline
\end{tabular}

The following machining conditions are assumed: - cutting speed, $v_{c}: 66.67 \mathrm{~m} / \mathrm{min}, 86.33 \mathrm{~m} / \mathrm{min}$, $100.00 \mathrm{~m} / \mathrm{min}, 116.67 \mathrm{~m} / \mathrm{min}, 133.33 \mathrm{~m} / \mathrm{min}$, $150.00 \mathrm{~m} / \mathrm{min}$,

- feed rate, $f: 0.10 \mathrm{~mm} / \mathrm{rev}, 0.20 \mathrm{~mm} / \mathrm{rev}, 0.28 \mathrm{~mm} /$ rev, $0.40 \mathrm{~mm} / \mathrm{rev}$,

- depth of cut, $a_{p}: 2 \mathrm{~mm}$.

The experimental tests were conducted in two stages. In the first stage, measurements were made during the tests in which the values of the components of the total cutting force were measured, and the value of the thermoelectric force signal generated at the contact between the cutting tool and the chip and thermographic images of the cutting zone were collected. In the second stage, i.e., after the end of the turning tests, the chip compression, length, and contact area were determined. The experimental tests 
were carried out on a stand based on the TUM-35D1 centre lathe (Fig. 1). Two dynamometers were used alternately: a tensometric dynamometer of our own design and a KISTLER 9257B dynamometer with suitable measuring equipment [12]. The mean contact temperature was measured using the natural singlepoint thermocouple method [18].

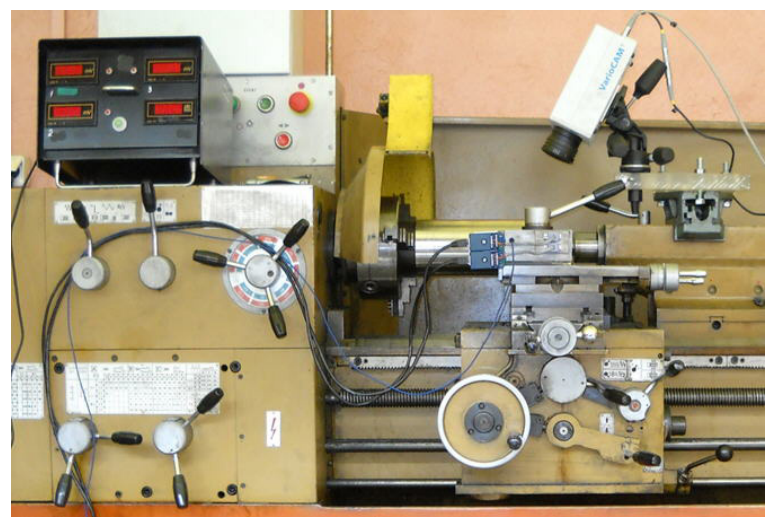

Fig. 1. View of the test bench

Thermographic images were collected using a JENOPTIK VarioCAM thermal imaging camera equipped with the IRBIS 3 software dedicated to archiving and processing thermographic images [12]. A sample image from an IR camera with a visible chip is shown in Fig. 2.

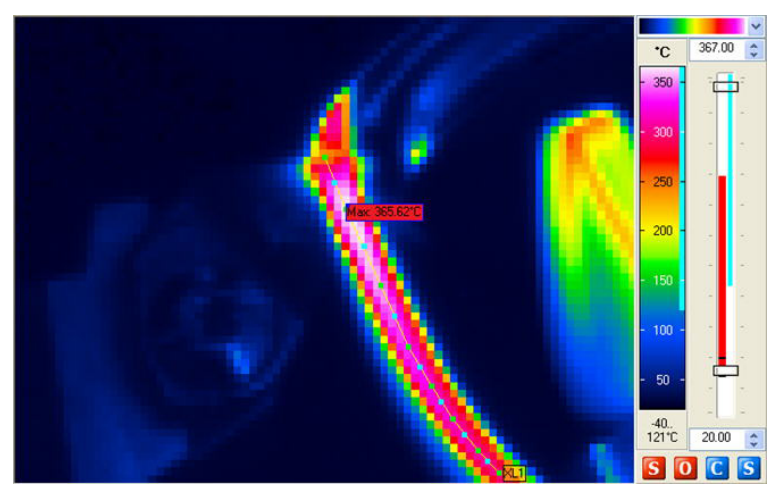

Fig. 2. A thermographic image of the cutting zone obtained at a cutting speed $v_{c}=100 \mathrm{~m} / \mathrm{min}$ and feed rate $f=0.20 \mathrm{~mm} / \mathrm{rev}$

Experimental tests of the cutting process were carried out on specimens in the form of a cylinder with undercut forming a short pipe with a wall thickness of $2 \mathrm{~mm}$. The requirement to isolate electrically the sample from the mechanisms of the machine tool was obtained using special insulating inserts made of dielectric materials. The LabVIEW software was used to record the tested signals.

\subsection{Workpiece Material}

The tests were carried out for one workpiece material, i.e., austenitic steel AISI 321 (DIN 1.4541). The quality of the material selected for testing was guaranteed by approval No MEST944800/2010/. Notwithstanding the above, the chemical composition of the material to be machined was tested experimentally. The results obtained are shown in Table 2.

The steel tested has a relatively low yield stress $R_{0.2}$ of $255 \mathrm{~N} / \mathrm{mm}^{2}$. In addition, this material has a high tendency to be reinforced by compression. After compression, the value of $R_{0.2}$ reaches from $1080 \mathrm{~N} /$ $\mathrm{mm}^{2}$ to $1370 \mathrm{~N} / \mathrm{mm}^{2}$. The metallographic structure of AISI 321 steel is shown in Fig. 3.

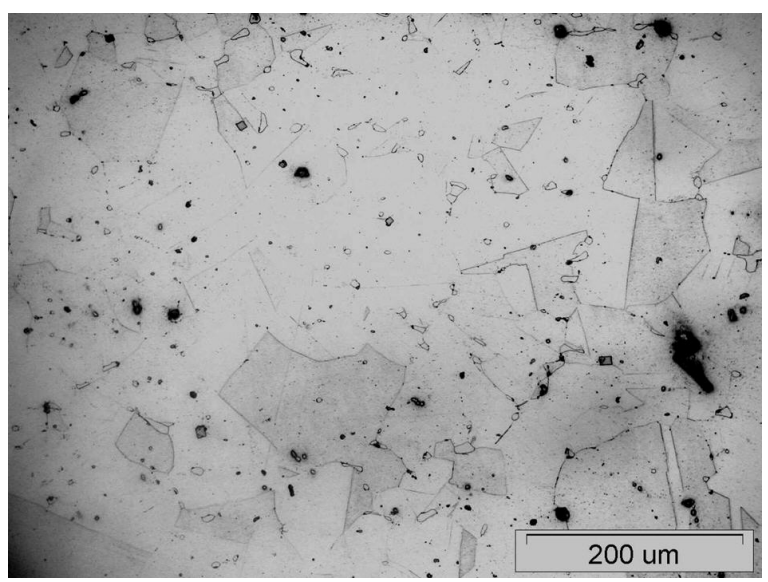

Fig. 3. Microstructure of AISI 321 steel at $\times 200$ magnification

The hardness of the material was measured before the tests started. The measurements were made using the Brinell test method, on a Zwick/Roell ZHV 10 hardness tester, with an indenter load (balls of 1 $\mathrm{mm}$ diameter) of $10 \mathrm{~kg}$. The average hardness value is $164 \mathrm{HB} \pm 5 \mathrm{HB}$.

Table 2. Alloying composition of AISI 321 steel determined by tests

\begin{tabular}{lcccccccccccccc}
\hline Alloying element & $\mathrm{Mn}$ & $\mathrm{Si}$ & $\mathrm{P}$ & $\mathrm{S}$ & $\mathrm{Cr}$ & $\mathrm{Ni}$ & $\mathrm{Mo}$ & $\mathrm{Cu}$ & $\mathrm{V}$ & $\mathrm{Al}$ \\
\hline Average content, [\%] & 1.63 & $\mathrm{O}$ & $\mathrm{C}$ & 0.007 & 0.014 & 17.31 & 9.29 & 0.36 & 0.43 & 0.062 & 0.025 \\
\hline Alloying element & $\mathrm{Ti}$ & $\mathrm{W}$ & $\mathrm{Co}$ & $\mathrm{Pb}$ & $\mathrm{Sn}$ & $\mathrm{As}$ & $\mathrm{B}$ & $\mathrm{N}$ & $\mathrm{Ca}$ & $\mathrm{Fe}$ \\
\hline Average content, [\%] & 0.309 & 0.029 & 0.116 & $<0.001$ & 0.010 & 0.003 & 0.0013 & $<0.001$ & 0.0017 & 69.70 \\
\hline
\end{tabular}




\subsection{Cutting Tool}

The H10F carbide cutting inserts from Sandvik Coromant used in the research have very good impact strength but relatively low abrasion resistance. These characteristics result from both the chemical composition and the grain size.

According to the manufacturer's data, $\mathrm{H} 10 \mathrm{~F}$ carbide consists of WC tungsten carbide (about $90 \%$ ) and cobalt (about $10 \%$ ) and the WC particle size of $<0.8 \mu \mathrm{m}$ classifies this material as fine carbide [2].

The chemical composition and microstructure of the cutting inserts tested were examined on the JEOL digital scanning electron microscope JSM-6460LV equipped with an EDS X-ray spectrometer. The image of the microstructure of the $\mathrm{H} 10 \mathrm{~F}$ tungsten carbide is shown in Fig. 4.

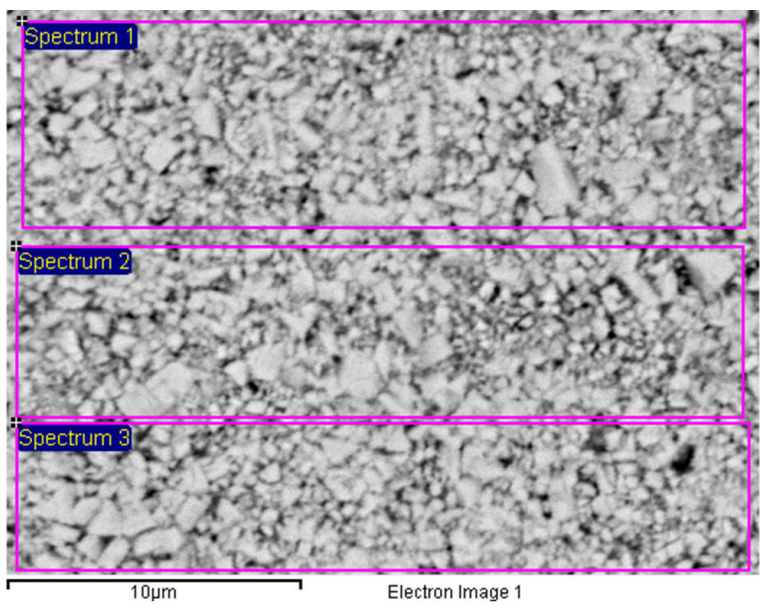

Fig. 4. BEC image of the H1OF tungsten carbide microstructure at $\times 5000$ magnification

The basic physical properties of the H10F carbide obtained from the literature are shown in Table 3. To complete the information, the hardness of the cutting insert was measured on its rake face. The tests were carried out using the Vickers method, on the Zwick/ Roell ZHV 10 hardness meter. The average measured hardness value of the H10F carbide is $1604 \mathrm{HV} \pm 16$ HV.

Table 3. Selected physical properties of the H1OF carbide according to [2]

\begin{tabular}{|c|c|c|c|c|c|c|}
\hline 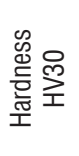 & 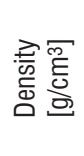 & 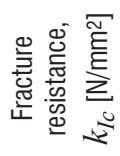 & 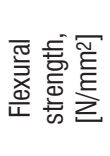 & 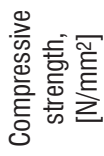 & 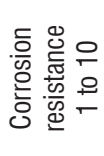 & 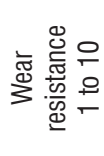 \\
\hline 1600 & 14.45 & 12.7 & 4300 & 6250 & 4 & 5 \\
\hline
\end{tabular}

\subsection{Measurement of the Temperature of Cutting by Natural Thermocouple}

In order to measure the average contact temperature using the single-point method, it was necessary to determine the characteristic $t=f(t e f)$ for the tested couple: carbide H10F - workpiece material AISI 321. This characteristic takes the following form:

$$
t=66.63299244 \cdot t e f+198.2808622 .
$$

The correlation coefficient for the above equation was 0.845 .

\subsection{Measurement of Contact Length}

In order to determine the length of contact and estimate the actual contact area after each turning test, a digital image of the abrasion area was taken on the LEICA MS 5 microscope. Measurements of the $l_{n c}$ contact length and planimetry of the $A_{k}$ contact area were performed using the LEICA IM 1000 Image Manager software.

\subsection{Numerical calculation}

These studies used a special variant of the FDM method called the method of elementary balances (MEB), in which differential equations are defined on the basis of energy balances for all discrete elements of the calculation model. This method uses only Fourier's law and a typical computational grid. In the presented studies, the calculations were made using Microsoft Excel. In the calculation, a grid with square elements of $5 \mu \mathrm{m}$ mesh size was used. Each cell in the calculation sheet is assigned to one discrete element of the analytical model. As a result, the model was built as a set of cells containing the relevant formulas and values. In this way, both the geometric and physical features of the modelled process are represented. Formulas are entered in accordance with the open differential procedure method [13].

The calculations were made for the twodimensional heat flow problem. Therefore, the partial differential equation for heat conduction in two perpendicular directions $x$ and $y$, expressed by the Fourier heat conduction law, can be recorded as a finite difference:

$$
\frac{T_{i-1, j}-2 T_{i, j}+T_{i+1, j}}{(\Delta x)^{2}}+\frac{T_{i-1, j}-2 T_{i, j}+T_{i+1, j}}{(\Delta y)^{2}}=0 .
$$



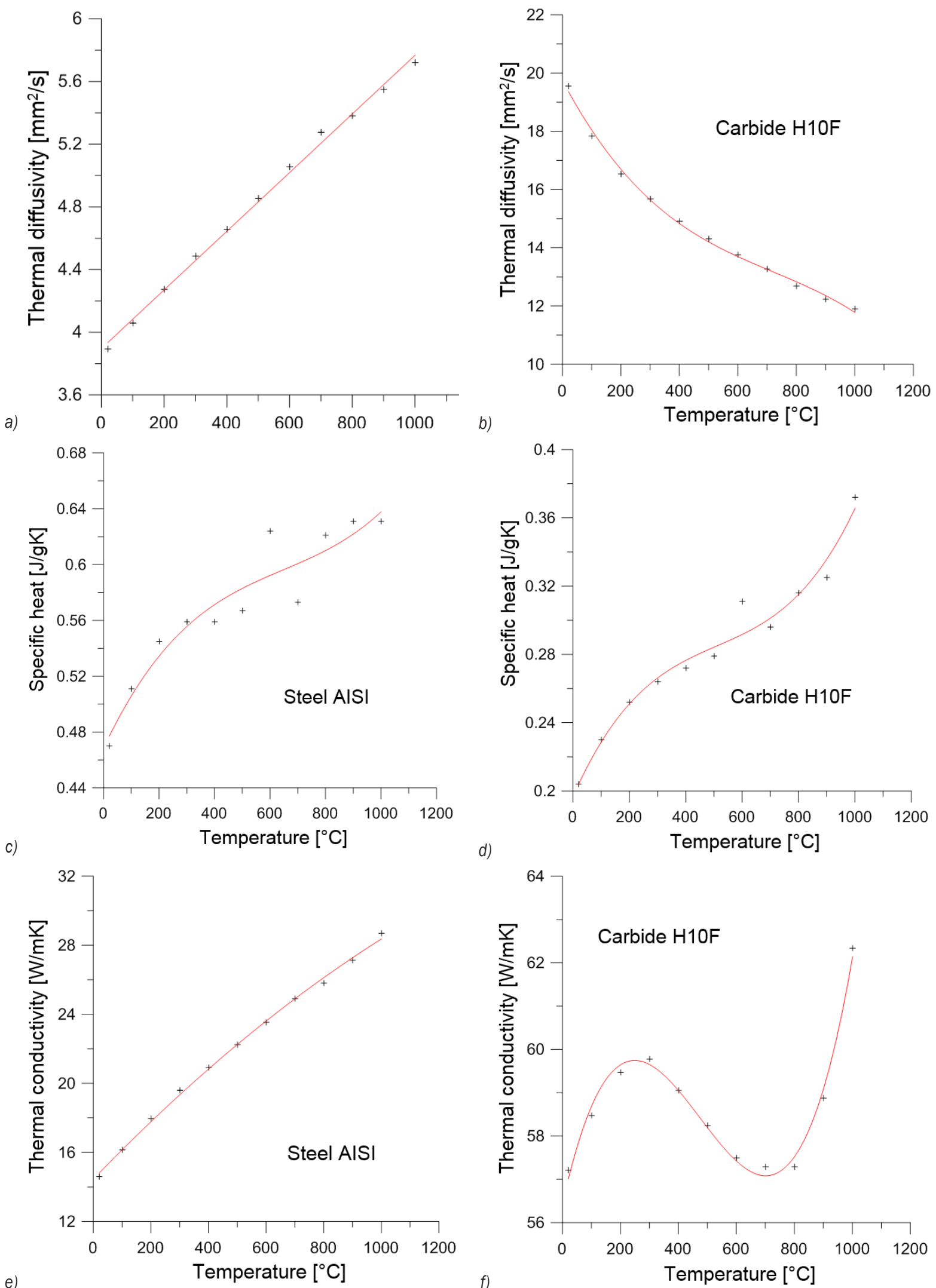

Fig. 5. Selected thermo-physical properties of the workpiece and tool material 
The difference equation can be solved numerically using eight specific linear and corner boundary conditions [13]. It should be noted that these calculations were carried out for time-varying and temperature-dependent thermo-physical properties of the cutting insert and material machined. Their numerical values were determined using the laserflash-technique using the LFA-457 MicroFlash from Netzsch. The graphic presentation of the thermophysical properties of the materials tested is shown in Fig. 5.

The density of both materials was also determined. It is respectively: $7.86 \mathrm{~g} / \mathrm{cm}^{3} \pm 0.02 \mathrm{~g} / \mathrm{cm}^{3}$ for the AISI 321 steel, and $14.33 \mathrm{~g} / \mathrm{cm}^{3} \pm 0.02 \mathrm{~g} / \mathrm{cm}^{3}$ for the $\mathrm{H} 10 \mathrm{~F}$ carbide. Thermal conductivity $\lambda(T)$ shown in Figs. $5 \mathrm{e}$ and $\mathrm{f}$ was calculated from the formula:

$$
\lambda(T)=\alpha(T) \cdot \rho \cdot c_{p}(T),
$$

where $\alpha(T)$ is thermal diffusivity as a function of temperature, and $c_{p}(T)$ a specific heat as a function of temperature.

The mathematical description of the discussed characteristics as a function of temperature is shown in Table 4.

In the first phase of calculations, the actual heat dissipation in the contact zone was mapped in the simulations. For this purpose, the so-called full calculation model was used, consisting of the cutting tool area and the moving chip (Fig. 6).

Two heat sources were defined in the calculation. Both heat sources were defined in the chip area. A plastic deformation heat source with a trapezoidal shape was defined on the slip plane (Fig. 7a). A triangular source of friction heat of the chip against the rake face was determined at the contact length (Fig. 7b). In these calculations, the division of the thermal fluxes between the chip and the cutting tool was spontaneous.

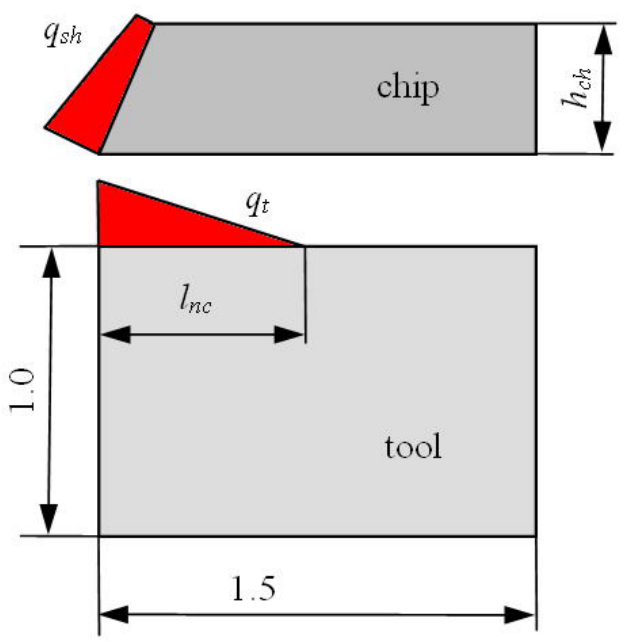

Fig. 6. Full calculation model - with a chip

In the second phase of simulation calculations, tests were conducted to estimate the actual amount of heat entering the tool through the length of contact. For this purpose, a simplified model was built, without the chip area (Fig. 8).

The density of the heat source $q_{n}$ was determined by the method of successive approximations, aiming at the same average contact temperature value as for the full model. Comparison of the heat flux intensity value for the full model (with a chip) with the heat flux intensity for the cutting tool itself (for the simplified model) enables determining the actual heat partition coefficient $R_{B}$.

Table 4. Equations of thermo-physical properties of the AISI 321 steel and $\mathrm{H} 10 \mathrm{~F}$ carbide in the temperature range $21^{\circ} \mathrm{C}$ to $1000{ }^{\circ} \mathrm{C}$

\begin{tabular}{|c|c|c|c|}
\hline Material & & Equation & $\begin{array}{l}\text { Correlation } \\
\text { coefficient }\end{array}$ \\
\hline \multirow{3}{*}{ AISI 321} & $\begin{array}{l}\text { Thermal diffusivity } \\
{\left[\mathrm{mm}^{2} / \mathrm{s}\right]}\end{array}$ & $Y=0.001871271133 \cdot X+3.896226402$ & 0.996 \\
\hline & $\begin{array}{l}\text { Specific heat } \\
{[\mathrm{J} /(\mathrm{gK})]}\end{array}$ & $Y=0.4684519516+0.000423468973 \cdot X-5.238734575^{-7} \cdot X^{2}+2.697322783^{-10} \cdot X^{3}$ & 0.903 \\
\hline & $\begin{array}{l}\text { Thermal conductivity } \\
{[\mathrm{W} /(\mathrm{mK})]}\end{array}$ & $Y=14.45503166+0.01727554457 \cdot X-3.37250283^{-6} \cdot X^{2}$ & 0.998 \\
\hline \multirow{3}{*}{$\mathrm{H} 10 \mathrm{~F}$} & $\begin{array}{l}\text { Thermal diffusivity } \\
{\left[\mathrm{mm}^{2} / \mathrm{s}\right]}\end{array}$ & $Y=19.74440671-0.01895773412 \cdot X+2.050360366^{-5} X^{2}-9.5090811^{-9} \cdot X^{3}$ & 0.997 \\
\hline & $\begin{array}{l}\text { Specific heat, } \\
{[\mathrm{J} /(\mathrm{gK})]}\end{array}$ & $Y=0.1965537097+0.0003752508169 \cdot X-5.93466171^{-7} \cdot X^{2}+3.871187722^{-10} \cdot X^{3}$ & 0.972 \\
\hline & $\begin{array}{l}\text { Thermal conductivity } \\
{[\mathrm{W} /(\mathrm{mK})]}\end{array}$ & $Y=56.41965076+0.03025415521 \cdot X-8.225706975^{-5} \cdot X^{2}+5.769878661^{-8} \cdot X^{3}$ & 0.985 \\
\hline
\end{tabular}


a)

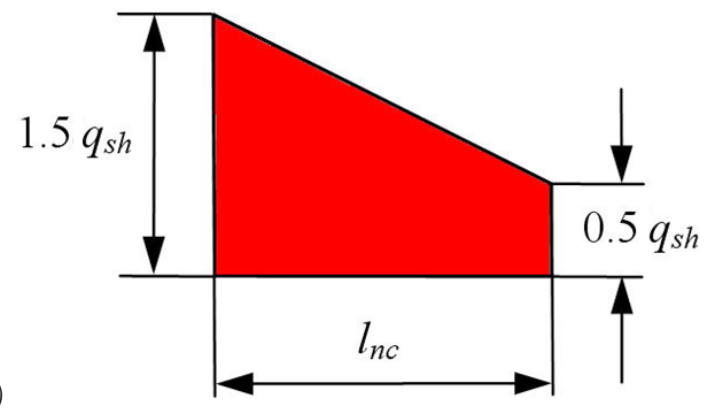

b)

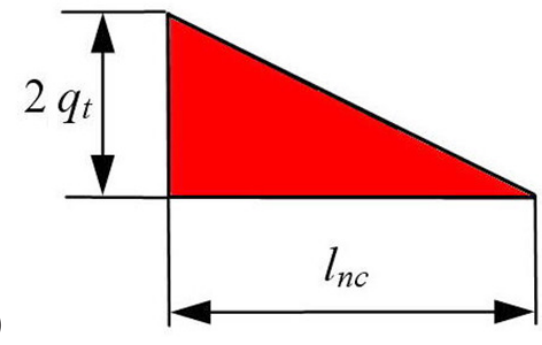

Fig. 7. Heat sources used in the tests; a) source of heat in the slip plane, and b) source of heat in the contact length

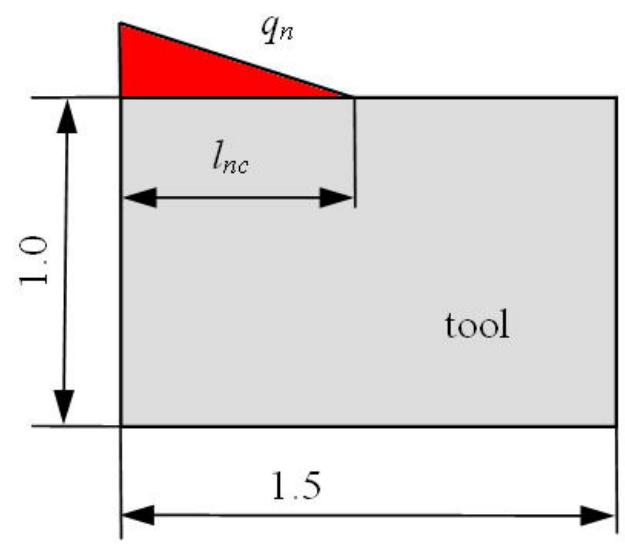

Fig. 8. Simplified model - without a chip

\section{RESULTS AND DISCUSSION}

\subsection{Experimental Studies}

The measured values of the components of the total cutting force, the average contact temperature and the maximum temperature of the chip upper side are shown in Table 5. The results were obtained for a variable cutting speed and feed rate of $0.2 \mathrm{~mm} / \mathrm{rev}$. After the end of the experiment, inter alia, the chip compression ratio $k_{h}$, the mechanical contact load $k_{F}$, the slip angle $\Phi$ and the slip coefficient $\mu$, the contact stress values $\sigma_{k}, \tau_{k}$ were calculated. These values were calculated on the basis of the previously measured chip thickness values $h_{c h}$, the contact area
$A_{k}$, the contact length $l_{n c}$ and the main cutting force components (peripheral force $F_{c}$ and feed force $F_{f}$ ). The study results collected in this way formed the basis for the construction of analytical and numerical models describing the heat dissipation in the cutting zone.

\subsection{Analytical Modelling}

Analytical modelling of thermal characteristics of the cutting process was carried out on the basis of commonly known relationships describing tribomechanical characteristics of the turning process [19]. The calculations focused on determining the average and maximum temperature values in the zone of primary plastic deformation (slip zone) and secondary plastic deformation (friction zone).

Generally speaking, due to the tool life, the maximum contact temperature seems to be the most important. Unfortunately, it cannot be measured. During the experimental studies, only information was collected about the value of the average contact temperature measured at the interface between the cutting tool and the workpiece material and about the temperature of the chip upper side. However, the maximum contact temperature that we are interested in can be determined with an analytical approach [4] and [5]. The detailed algorithm of conducted analytical calculations and interrelationships between the calculation formulas are shown in Fig. 9.

According to the algorithm presented, in order to calculate the maximum contact temperature, it is necessary to know the average and maximum temperature in the zone of primary and secondary plastic deformation. Temperatures generated in the zone of primary plastic deformation were determined according to the methodology proposed by Silin [5].

A comprehensive graphical representation of the algorithm for determining the thermal characteristics of the cutting process is shown in Fig. 9. In contrast, the numerical values of the average and maximum contact temperature calculated for cutting with a constant feed rate $f=0.20 \mathrm{~mm} / \mathrm{rev}$ and a variable cutting speed are shown in Table 5. It should be noted that the calculations were made taking into account the influence of temperature on the thermo-physical properties of both materials tested. A graphical comparison of the sample calculation results with the experimentally obtained data is shown in Fig. 10. The dashed line on the graphs shows the average contact temperature determined experimentally, whereas the solid line shows the result of analytical modelling. Modelling of the temperature of the contact $t_{k}$ and the 
maximum temperature of the contact $t_{k \max }$ was carried out according to the formulas shown in Fig. 9.
The analysis of the distribution of the presented temperature curves shows that for the H10F cutting

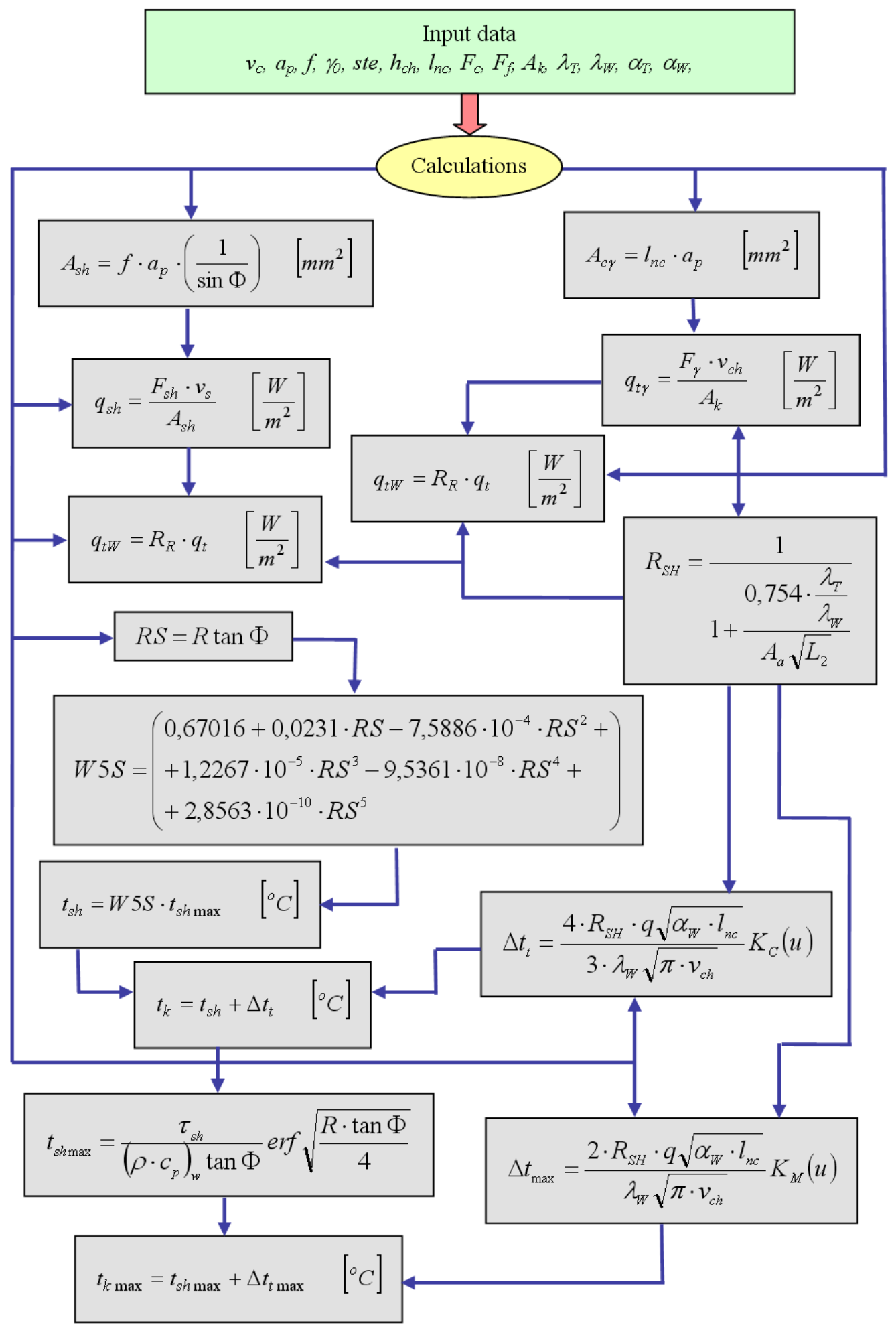

Fig. 9. Algorithm for determining the thermal characteristics of the cutting process 
insert without protective coatings the value of the average contact temperature determined analytically is about $20 \%$ to $25 \%$ lower than the value obtained by way of experimentation. It can be assumed that the source of discrepancies between the measured and modelled average contact temperature value lies mainly in the adopted calculation methodology and, above all, in the imperfections of commonly known heat partition coefficients and in the analytical models themselves, as indicated by the research conducted by Niesłony [19].

Table 5. Summary of calculated average and maximum contact temperature values for a variable cutting speed and feed rate of $0.2 \mathrm{~mm} / \mathrm{rev}$

\begin{tabular}{cccccccc}
\hline \multirow{2}{*}{$\begin{array}{c}f \\
{[\mathrm{~mm} / \mathrm{rev}]}\end{array}$} & $\begin{array}{c}v_{c} \\
{[\mathrm{~m} / \mathrm{min}]}\end{array}$ & $\begin{array}{c}F_{c} \\
{[\mathrm{~N}]}\end{array}$ & $\begin{array}{c}F_{f} \\
{[\mathrm{~N}]}\end{array}$ & $\begin{array}{c}t_{k} \\
{\left[{ }^{\circ} \mathrm{C}\right]}\end{array}$ & $\begin{array}{c}t_{W \max } \\
{\left[{ }^{\circ} \mathrm{C}\right]}\end{array}$ & $\begin{array}{c}t_{k} \\
{\left[{ }^{\circ} \mathrm{C}\right]}\end{array}$ & $\begin{array}{c}t_{k \max } \\
{\left[{ }^{\circ} \mathrm{C}\right]}\end{array}$ \\
\hline 0.20 & 66.67 & 1369.4 & 1085.5 & 880.0 & 367.3 & 650.0 & 960.1 \\
\hline 0.20 & 86.33 & 1274.7 & 959.4 & 912.4 & 376.5 & 696.9 & 1031.3 \\
\hline 0.20 & 100.00 & 1212.7 & 887.7 & 931.0 & 381.8 & 732.1 & 1088.7 \\
\hline 0.20 & 116.67 & 1141.2 & 812.5 & 949.4 & 387.3 & 757.6 & 1135.4 \\
\hline 0.20 & 133.33 & 1074.0 & 747.3 & 963.1 & 392.1 & 774.6 & 1173.4 \\
\hline 0.20 & 150.00 & 1010.7 & 689.9 & 972.0 & 396.3 & 784.4 & 1204.3 \\
\hline
\end{tabular}

Based on literature data [1] and [2] and the results of the calculations carried out, it can be concluded that the heat generated in the zone of the primary plastic deformation and then accumulated in the chip is almost entirely carried away with the chip.

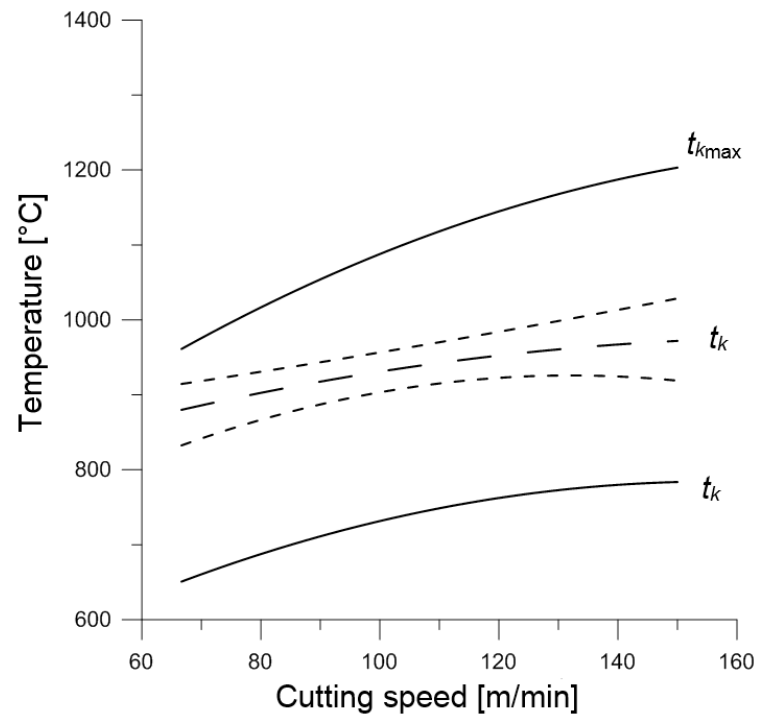

Fig. 10. Average and maximum contact temperature for the H1OF cutting tool (without coatings), solid lines - data from analytical models, dashed line - experimental data
Some of it, however, penetrates the cutting tool through the contact area, combining with the heat of friction between the chip and the rake face of the cutting tool. The amount of heat entering the tool in this way can be calculated analytically using the heat partition coefficients (according to Shaw [3], Reznikov [4], or Kato-Fujii heat partition coefficient [5]. However, it must be remembered that these coefficients of heat give a clear underestimation of the total heat flux penetrating the cutting edge of the tool [10] and [12]. Moreover, they are highly sensitive to the correct selection of material data.

\subsection{Simulation Modelling}

The results of numerical modelling carried out according to the procedure described above are shown in Table 6. The comparison of the average contact temperature measurements and the numerical calculation results obtained for the full model (with a chip) shows that the largest discrepancies in the results were recorded for low cutting speeds, respectively $-5.0 \%$ for $v_{c}=83.33 \mathrm{~m} / \mathrm{min}$ and $-11.31 \%$ for $v_{c}=66.67 \mathrm{~m} / \mathrm{min}$.

Table 6. Summary of the results of simulations of heat dissipation in the contact zone for the uncoated H1OF cutting insert for a variable cutting speed and feed rate of $0.2 \mathrm{~mm} / \mathrm{rev}$

\begin{tabular}{cccccc}
\hline & $\begin{array}{c}t_{k} \\
v_{c} \\
{[\mathrm{~m} / \mathrm{min}]}\end{array}$ & $\begin{array}{c}t_{k} \\
{\left[{ }^{\circ} \mathrm{C}\right]}\end{array}$ & $\begin{array}{c}\text { Deviation } \\
{[\%]}\end{array}$ & $\begin{array}{c}t_{k} \\
{\left[{ }^{\circ} \mathrm{C}\right]}\end{array}$ & $\begin{array}{c}\text { Deviation } \\
{[\%]}\end{array}$ \\
\cline { 2 - 6 } & Experiment & \multicolumn{2}{c}{$\begin{array}{c}\text { Simulation }- \\
\text { full model }\end{array}$} & \multicolumn{2}{c}{$\begin{array}{c}\text { Simulation }- \\
\text { simplified model }\end{array}$} \\
\hline 66.67 & 880.0 & 780.50 & -11.31 & 780.80 & -11.27 \\
\hline 83.33 & 912.4 & 862.50 & -5.00 & 861.64 & -5.10 \\
\hline 100.00 & 931.0 & 924.85 & -0.66 & 925.02 & -0.64 \\
\hline 116.67 & 949.4 & 970.33 & 2.20 & 970.50 & 2.22 \\
\hline 133.33 & 963.1 & 1010.39 & 4.91 & 1012.31 & 5.11 \\
\hline 150.00 & 972.0 & 1032.13 & 6.19 & 1030.12 & 5.98 \\
\hline
\end{tabular}

This phenomenon probably results from the shape of the heat source, adopted for the calculations, defined at the slip plane and at the contact length [10]. Another reason for these differences may be the longer stabilization time of the model at low cutting speeds. Assuming that the obtained differences in the results are acceptable, simulations of heat distribution were performed for the simplified model (without a chip). The calculations were carried out by selecting the intensity of the heat source in such a way as to get as close as possible to the results obtained in the first simulation round (for the full model). A comparison of the contact temperature values for the experiment and both simulation models is shown in Table 6 . 
It can be noted that for both numerical models very similar deviation values were obtained, whereas Table 7 presents the thermal flux figures for the full $\left(q_{t}\right)$ and simplified $\left(q_{n}\right)$ models. A graphical comparison of the variation in the intensity of both these heat fluxes as a function of cutting speed is shown in Fig. 11. The analysis of the course of change of both heat fluxes indicates that the actual value of the heat flux $q_{n}$ penetrating the cutting tool surface through the contact length is lower than the friction heat flux $q_{t}$ by about $25 \%$ for low cutting speeds and about $55 \%$ for high speeds. This phenomenon can be explained in part by the ratio of thermo-physical properties of the workpiece material and the cutting tool material and in part by the influence of the cutting speed on the division of the thermal fluxes in the zone of cutting.

Table 7. Summary of the frictional heat flux values for the full and simplified model, for the H1OF cutting tool without coatings; machining parameters: $v_{c}=$ vario, $f=0.2 \mathrm{~mm} / \mathrm{rev}$

\begin{tabular}{cccc}
\hline$v_{c}$ & $q_{t}\left[\mathrm{MW} / \mathrm{m}^{2}\right]$ & $q_{n}\left[\mathrm{MW} / \mathrm{m}^{2}\right]$ & \\
\cline { 2 - 3 }$[\mathrm{m} / \mathrm{min}]$ & $\begin{array}{c}\text { Simulation } \\
\text { full model }\end{array}$ & $\begin{array}{c}\text { Simulation } \\
\text { simplified } \\
\text { model }\end{array}$ & $q_{n} / q_{t}=R_{B}$ \\
\hline 66.67 & 137.694 & 104.796 & 0.761076 \\
\hline 83.33 & 178.315 & 130.477 & 0.731726 \\
\hline 100.00 & 221.789 & 137.144 & 0.618352 \\
\hline 116.67 & 269.060 & 151.603 & 0.563453 \\
\hline 133.33 & 321.581 & 163.797 & 0.509350 \\
\hline 150.00 & 381.783 & 176.664 & 0.462733 \\
\hline
\end{tabular}

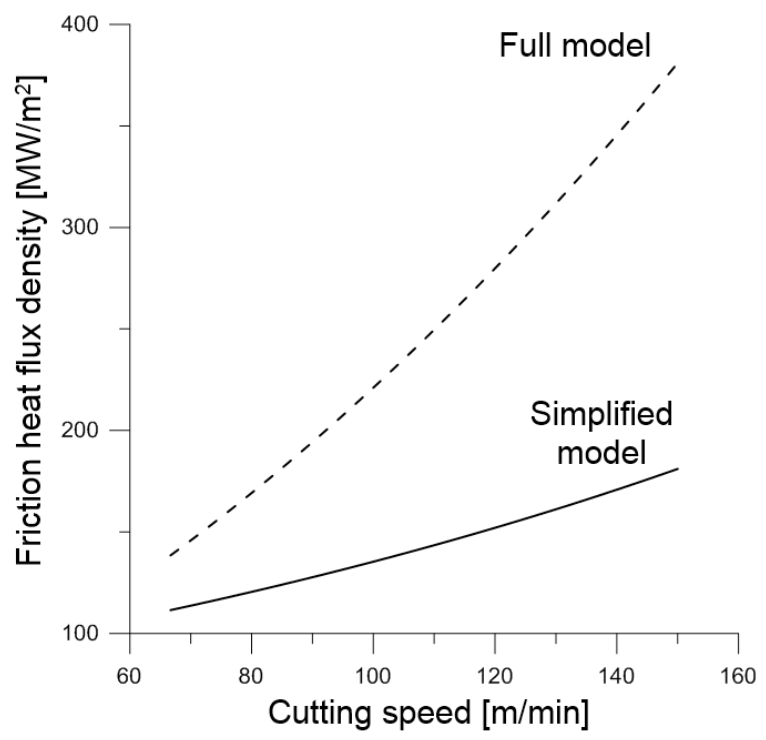

Fig. 11. Influence of the cutting speed on changes in frictional heat flux density, machining parameters:

$$
v_{c}=\text { vario, } a_{p}=2 \mathrm{~mm}, f=0.2 \mathrm{~mm} / \mathrm{rev}
$$

It is important to remember that as the cutting speed increases, the heat flux of friction and heat of plastic deformation does so also, while at the same time the contact length decreases and the chip evacuation speed increases. This phenomenon shortens the duration of the influence of the thermal fluxes on the cutting insert. As a result, the total amount of heat penetrating the cutting tool is significantly reduced. The analysis of the mutual ratio of the heat fluxes $q_{t}$ to $q_{n}$ (Fig. 11) shows that as the cutting speed increases, the actual amount of heat entering the tool through the contact length decreases, which means that the heat partition coefficient will also decrease as the cutting speed increases. These results are confirmed in the literature, because a decrease in the partition coefficient with an increase in the $v_{c}$ speed was proved earlier by Jinfu and Liu [16] and Zemzemi et al. [17].

From the analysis of the simulation results (Table 7) and the course of changes calculated analytically and determined in the simulations of the actual friction heat flux density (Fig. 11) it can be seen that the ratio of the value of the actual heat flux penetrating the tool $q_{n}$ to the value of the friction heat flux $q_{t}$ may be a new value of the heat partition coefficient $R_{B}$. The new heat partition coefficient figures calculated in this way are shown in Table 7.

Analysis of the calculation formulas on the commonly known heat partition coefficients indicates that they are based almost exclusively on the mutual ratio of thermophysical properties of the workpiece and tool material. This approach seems to be correct because, as we know, it is the thermo-physical properties that mainly determine the heat distribution in the cutting zone. On the basis of the abovementioned assumptions, a new formula of the heat partition coefficient $R_{B}$ was developed, describing in a more rational way the heat distribution for carbide cutting tools without protection coatings. Its form can be recorded as follows:

$$
R_{B}=-11.009 \cdot \ln \frac{b_{T}}{b_{W}}+4.499,
$$

where $b_{T}$ is heat transfer coefficient for the tool, $b_{T}=\sqrt{\lambda_{T} \cdot \rho_{T} \cdot c_{p T}}$, and $b_{W}$ heat transfer coefficient for the chip, $b_{W}=\sqrt{\lambda_{W} \cdot \rho_{W} \cdot c_{p W}}$.

The algorithm of the calculations carried out for this purpose is illustrated in Fig. 12.

The course of changes in the value of the new heat partition coefficient $R_{B}$ calculated from Eq. (4) is shown as a function of the cutting speed in Fig. 13. For comparison, this graph shows the changes of commonly known literature-derived heat partition 


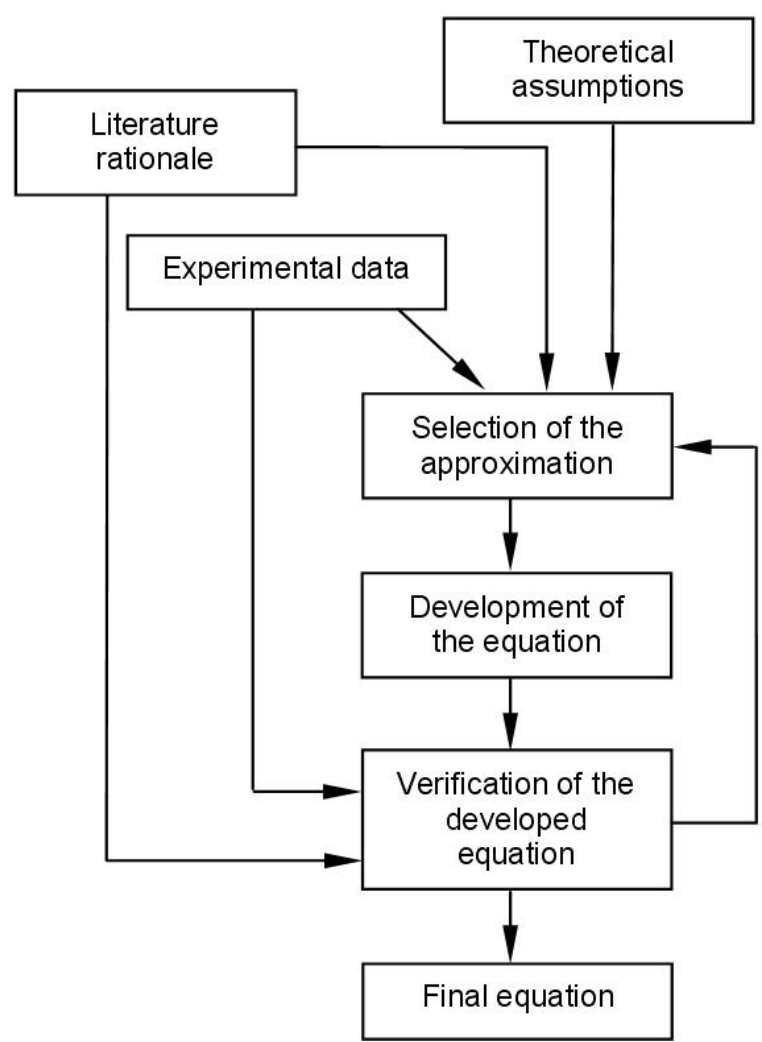

Fig. 12. Algorithm for determining the heat partition coefficient equation

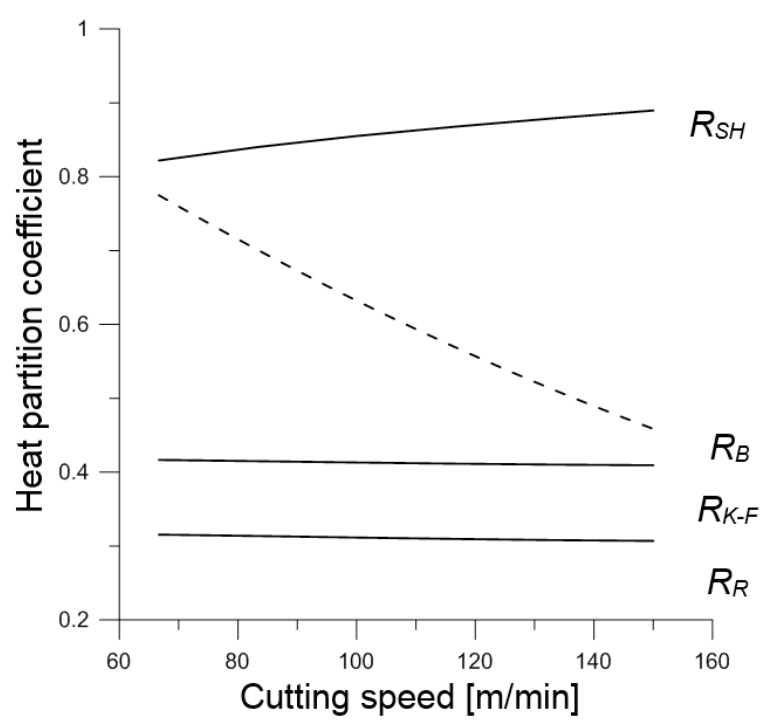

Fig. 13. Course of change of different heat partition coefficients for the pair AISI321 steel-uncoated carbide, machining parameters: $v_{c}=$ vario, $a_{p}=2 \mathrm{~mm}, f=0.2 \mathrm{~mm} / \mathrm{rev}$

coefficients according to Shaw [3], Reznikov [4] and Kato-Fujii heat partition coefficient [5]. Note that the $R_{B}$ value varies monotonously from 0.76 for $v_{c}$ from
$66 \mathrm{~m} / \mathrm{min}$ to $0.46 \mathrm{~m} / \mathrm{min}$ for a cutting speed of 150 $\mathrm{m} / \mathrm{min}$. The nature of these changes is completely different from the other heat partition coefficients.

The analysis of the distribution of the curves shows that the calculations demonstrated a relatively large discrepancy in the results, reaching $-23 \%$ for a cutting speed of $150 \mathrm{~m} / \mathrm{min}$. Therefore, the new heat partition coefficient does not match Shaw's empirical patterns. Thus, for the calculation of the average contact temperature, a new formula based on the law of heat conduction was proposed:

$$
t_{k}=\frac{q_{n}}{\lambda_{w}} \cdot l_{p},
$$

where $l_{p}$ is the length of the plastic interface.

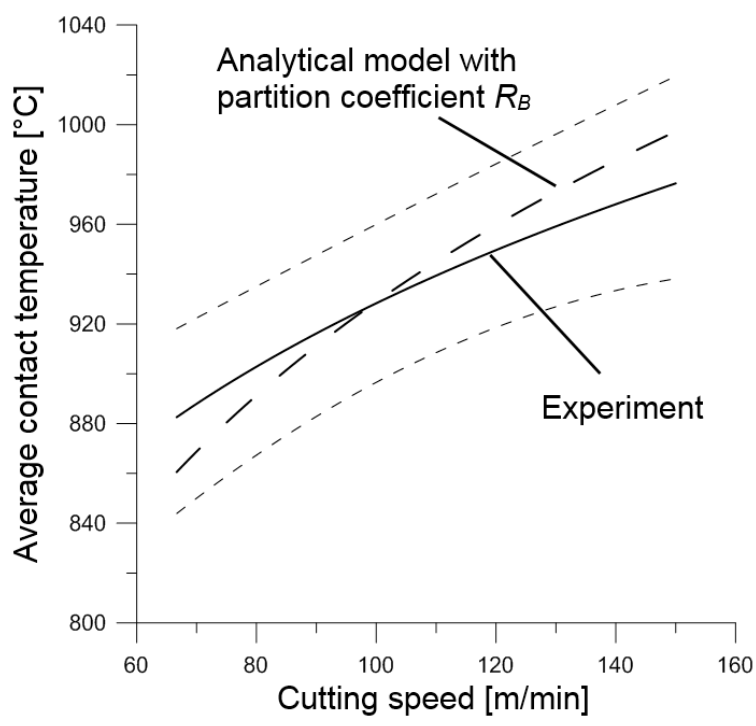

Fig. 14. Comparison of the average contact temperature measured experimentally and determined from the law of heat conduction for the new partition coefficient, cutting tool: H1OF without coatings, machining parameters:

$$
v_{c}=\text { vario, } a_{p}=2 \mathrm{~mm}, f=0.2 \mathrm{~mm} / \mathrm{rev}
$$

Based on the literature data [1] and [20] and, in particular, the results of previous research [10] and [12], the plastic interface length $l_{p}=0.37 \cdot l_{n c}$, identical for all cases considered, was assumed for the calculations. The calculations performed according to Eq. (5) for the constant $l_{p}$ value and using the new heat partition coefficient $R_{B}$ are graphically shown in Fig. 14. This figure shows a comparison of the average contact temperature obtained from the calculations and from the experiment. Both graphs show a high level of alignment. The greatest temperature differences of about $3.5 \%$ were recorded for extreme cutting speeds. It can be assumed that this error is due to the assumption of a constant value of the plastic interface 
length $l_{p}$. In reality, $l_{p}$ is not a constant quantity. It changes its value to a small extent as the cutting speed changes. In Eq. (5) the parameter $l_{p}$ is a component of the product, therefore even a slight change in its value will translate into the final result.

\section{CONCLUSIONS}

The analysis of heat distribution in the cutting zone shown in this article allows for the following conclusions:

- The maximum temperature of the chip upper side, as well as the average cutting temperature determined in experimental studies, can be successfully used to validate numerical calculations. The research has proven that the temperature of the chip upper side represents about $50 \%$ of the average contact temperature measured experimentally, whereas the difference between the average contact temperature determined experimentally and calculated in simulations ranges from $-11.3 \%$ to $+6.2 \%$.

- The developed formula of the new heat partition coefficient $R_{B}$ at the chip-to-cutting tool interface is based exclusively on the interrelationship of thermophysical properties of the cutting tool and workpiece material. The influence of the cutting speed is taken into account indirectly, by changing the temperature-dependent values of the thermophysical properties. Unlike other known heat partition coefficients, its value decreases monotonically as the cutting speed increases and changes between 0.76 (for $v_{c}=66 \mathrm{~m} / \mathrm{min}$ ) and 0.46 (for $v_{c}=150 \mathrm{~m} / \mathrm{min}$ ).

- The new formula for average contact temperature was derived from Fourier's law and is much simpler than the empirical formulas used so far. The calculations made with its help and using the new heat partition coefficient $R_{B}$ are characterized by an error not exceeding $3.5 \%$.

\section{REFERENCES}

[1] Grzesik, W. (2017). Advanced Machining Processes of Metallic Materials: Theory, Modelling, and Applications, Elsevier, Amsterdam.

[2] Davim, J.P. (2010). Metal Cutting, Nova Science Publishers Inc., New York

[3] Shaw, M.C. (2004). Metal cutting principles, Oxford University Press, Oxford.

[4] Reznikov, A.N. (1981). Thermophysics of Metal Machining Processes, Mechanical Engineering, Moscow. (in Russian)

[5] Silin, S.S. (1979). Similarity Method when Cutting Materials, Mechanical Engineering, Moscow. (in Russian)
[6] Venkatesh, S.S., Ram Kumar, T.A., Blalakumhren, A.P., Saimurugan, M., Prakash Marimuthu K. (2019). Finite element simulation and experimental validation of the effect of tool wear on cutting forces in turning operation. Mechanics and Mechanical Engineering, vol. 23, no. 1, p. 297-302, DOl:10.2478/mme-2019-0040.

[7] Zhang, Q., Zhang, S., Li, J. (2017). Three dimensional finite element simulation of cutting forces and cutting temperature in hard milling of AISI H13 steel. Procedia Manufacturing, vol. 10, p. 37-47, DOI:10.1016/j.promfg.2017.07.018.

[8] Pattavanitch, J., Hinduja, S., Atkinson, J. (2010). Modelling of the electrochemical machining process by the boundary element method. CIRP Annals, vol. 59, no. 1, p. 243-246, DOl:10.1016/j.cirp.2010.03.072.

[9] Zhang, Y., Gu, Y., Chen, J.T. (2010). Boundary element analysis of the thermal behaviour in thin-coated cutting tools. Engineering Analysis with Boundary Elements, vol. 34, no. 9, p. 775-784, D0I:10.1016/j.enganabound.2010.03.014.

[10] Bartoszuk, M., Grzesik, W. (2011). Numerical prediction of the interface temperature using updated Finite Difference Approach, CIRP Annals - Advanced Materials Research, vol. 223, p. 231-239, D0l:10.4028/www.scientific.net/ AMR.223.231.

[11] Niu, W., Mo, R., Liu, G.R., Sun, H., Dong, X., Wang, G. (2017). Modeling of orthogonal cutting process of A2024-T351 with an improved SPH method. The International Journal of Advanced Manufacturing Technology, vol. 95, p. 905-919, D0l:10.1007/ s00170-017-1253-6.

[12] Bartoszuk, M. (2013). Modeling of Heat Flow and Temperature Distribution in the Cutting Zone for Cemented Carbide Inserts, Publishing House of the Opole University of Technology, Opole. (in Polish)

[13] Grzesik, W., Bartoszuk, M., Niesłony, P. (2004). Finite difference analysis of the Thermal bahaviour of coated tools in orthogonal cutting of steels. International Journal of Machine Tools and Manufacture, vol. 44, no. 14, p. 1451-1462, D0I:10.1016/j.ijmachtools.2004.05.008.

[14] Jam, J.E., Fard, V.N. (2011). A novel method to determine toolchip thermal contact conductance in machining, International Journal of Engineering Science and Technology, vol. 3, no. 12, p. 8491-8501.

[15] Jin, D., Jingjie, Z., Liguo, W. (2018). Heat partition and rake face temperature in the machining of $\mathrm{H} 13$ steel with coated cutting tools. The International Journal of Advanced Manufacturing Technology, vol. 94, p. 3691-3702, D0l:10.1007/s00170-0171122-3.

[16] Zhao, J., Liu, Z. (2019). Modelling for prediction of timevarying heat partition coefficient at coated tool-chip interface in continuous turning and interrupted milling. International Journal of Machine Tools \& Manufacture, vol. 147, p. 1-10, DOl:10.1016/J.ijmachtools.2019.103467.

[17] Zemzemi, F., Rech, J., Ben Salem, W., Dogui, A., Kapsa, Ph. (2014). Identification of friction and heat partition model at the tool-chip-workpiece interfaces in dry cutting of an inconel 718 alloy with CBN and coated carbide tools. Advances in Manufacturing Science and Technology, vol. 38, no.1, p. 5-22, DOI:10.2478/amst-2014-0001. 
[18] Abhang, L.B., Hameedullah, M. (2010). Chip-tool interface temperature prediction model for turning process. International Journal of Engineering Science and Technology, vol. 2, no. 4, p. 382-393.

[19] Niesłony, P. (2008). Modeling of Heat Flow and Temperature Distribution in the Cutting Zone for Blades with Hard Protective
Coatings, Publishing House of Opole University of Technology, Opole. (in Polish)

[20] Markopoulos, A.P., Davim, J.P. (2018). Advanced Machining Processes: Innovative Modeling Techniques, CRC Press, Taylor \& Francis Group, Boca Raton. 